\title{
Effects of THBS3, SPARC and SPPI expression on biological behavior and survival in patients with osteosarcoma
} Cristiane A Dalla-Torre ${ }^{1,2}$, Maisa Yoshimoto ${ }^{3}$, Chung-Hae Lee $^{3}$, Anthony M Joshua ${ }^{3}$, Silvia RC de Toledo ${ }^{1,2}$, Antônio S Petrilli1, Joyce AD Andrade ${ }^{2}$, Susan Chilton-MacNeill ${ }^{4}$, Maria Zielenska ${ }^{4,5}$ and Jeremy A Squire*3,5

\author{
Address: ${ }^{1}$ Department of Pediatrics, Instituto de Oncologia Pediátrica (IOP-GRAACC), Universidade Federal de São Paulo, Escola Paulista de \\ Medicina, São Paulo 04023-062, Brazil, ²Department of Morphology, Division of Genetics, Universidade Federal de São Paulo, Escola Paulista de \\ Medicina, São Paulo 04023-900, Brazil, ${ }^{3}$ Applied Molecular Oncology, Ontario Cancer Institute, Princess Margaret Hospital, Toronto, Ontario \\ M5G 2M9, Canada, ${ }^{4}$ Department of Pediatric Laboratory Medicine, The Hospital for Sick Children, Toronto, Ontario M5G 1X8, Canada and \\ ${ }^{5}$ Department of Laboratory Medicine and Pathobiology, University of Toronto, Toronto, Ontario M5G 2M9, Canada \\ Email: Cristiane A Dalla-Torre - genetica@graacc.org.br; Maisa Yoshimoto - myoshimo@uhnres.utoronto.ca; Chung- \\ Hae Lee - clee@uhnres.utoronto.ca; Anthony M Joshua - anthony.joshua@doctor.com; Silvia RC de Toledo - genetica@graacc.org.br; \\ Antônio S Petrilli - iopepm@dialdata.com.br; Joyce AD Andrade - genetica@graacc.org.br; Susan Chilton-MacNeill - susan.chilton- \\ macneill@sickkids.ca; Maria Zielenska - m.zielenska@utoronto.ca; Jeremy A Squire* - jeremy.squire@utoronto.ca \\ * Corresponding author
}

Published: 05 October 2006

BMC Cancer 2006, 6:237 doi:10.1/86/147|-2407-6-237
Received: 03 May 2006

Accepted: 05 October 2006

This article is available from: http://www.biomedcentral.com/I47I-2407/6/237

(C) 2006 Dalla-Torre et al; licensee BioMed Central Ltd.

This is an Open Access article distributed under the terms of the Creative Commons Attribution License (http://creativecommons.org/licenses/by/2.0), which permits unrestricted use, distribution, and reproduction in any medium, provided the original work is properly cited.

\begin{abstract}
Background: Osteosarcoma is a very aggressive tumor with a propensity to metastasize and invade surrounding tissue. Identification of the molecular determinants of invasion and metastatic potential may guide the development of a rational strategy for devising specific therapies that target the pathways leading to osteosarcoma.

Methods: In this study, we used pathway-focused low density expression cDNA arrays to screen for candidate genes related to tumor progression. Expression patterns of the selected genes were validated by real time PCR on osteosarcoma patient tumor samples and correlated with clinical and pathological data.

Results: THBS3, SPARC and SPPI were identified as genes differentially expressed in osteosarcoma. In particular, THBS3 was expressed at significantly high levels $(p=0.000 \mathrm{I})$ in biopsies from patients with metastasis at diagnosis, which is a predictor of worse overall survival, event-free survival and relapse free survival at diagnosis. After chemotherapy, patients with tumors overexpressing THBS3 have worse relapse free survival. High SPARC expression was found in $51 / 55$ (96.3\%) osteosarcoma samples derived from 43 patients, and correlated with the worst event-free survival $(p=0.03)$ and relapse free survival $(p=0.07)$. Overexpression of SPPI was found in 47 of $53(89 \%)$ osteosarcomas correlating with better overall survival, event-free survival and relapse free survival at diagnosis.

Conclusion: In this study three genes were identified with pattern of differential gene expression associated with a phenotypic role in metastasis and invasion. Interestingly all encode for proteins involved in extracellular remodeling suggesting potential roles in osteosarcoma progression. This is the first report on the THBS3 gene working as a stimulator of tumor progression. Higher levels of THBS3 maintain the capacity of angiogenesis. High levels of SPARC are not required for tumor progression but are necessary for tumor growth and maintenance. SPPI is not necessary for tumor progression in osteosarcoma and may be associated with inflammatory response and bone remodeling, functioning as a good biomarker.
\end{abstract}




\section{Background}

Osteosarcoma (OS) is a rare tumor of children and young adults. The peak of incidence occurs in the second decade of life [1]. In Brazil, it is estimated that a total of 350 new cases of OS are diagnosed per year [2], with metastasis in $20.9 \%$ of the cases. The presence of metastases at diagnosis is the most significant isolated factor influencing survival in this group [3]. Lung metastases appear in almost 40 to $50 \%$ of the patients with OS, and are the major cause of death [4]. The degree of necrosis following definitive surgery is a consistent prognostic factor [5].

Metastases consist of a series of sequential steps, all of which must be successfully completed. These include shedding of cells from a primary tumor into the circulation, survival of the cells in the circulation, arrest in a new organ, extravasations into the surrounding tissue, initiation and maintenance of growth, and vascularization of the metastatic tumor [6]. The successful metastatic cells must possess a set of particular characteristics that are different from non-metastatic tumor cells, enabling them to complete each step in the metastatic sequence [7].

Knowledge on the biology of the metastatic process is limited. Some molecular factors have been identified as contributing to the formation of detectable metastases, and additional factors hopefully will be soon identified using microarray expression profiling [6]. The pathway-focused GEArray $^{\circledast}$ is a useful way to perform both highly sensitive and precise large-scale analysis of the expression level of various genes $[8,9]$. The advantage of using this technology is that a defined set of genes closely-related to a specific process, biological behavior or biomarker can be screened with limited sample material, as observed by [10-12]. Through these comparisons, a list of genes differentially expressed and potentially important for the process is easily derived that can be validated by other techniques. The biomarkers may become tools for establishing early diagnosis and designing therapeutic targets in specific cancers.

By comparing the highly metastatic K7M2 and $\mathrm{K} 12$ murine osteosarcoma cell lines using cDNA microarray technology, Khanna et al. [13] identified 10 potential genes involved in the metastatic process in osteosarcoma: ITGB4 (integrin $\beta 4$ ), CTGF (connective tissue growth factor), ITGA5 (integrin $\alpha 5$ ), VIL2 (ezrin), ITGB2 (integrin B2), LGALS3 (galectin-3), ADAM8 (a disintegrin and metalloprotease domain 8), CLU (clusterin), FARP1 (FERM, RhoGEF, and pleckstrin domain protein 1 isoform 1) and $C P$ (ceruloplasmin). These genes are involved in motility/ cytoskeleton, heterotypic adherence and/or angiogenesis [13].
Genes identified in this work include those not described previously in OS as well as potentially novel metastasisassociated genes. Functional studies suggest that 10 genes associated with motility/cytoskeleton, heterotypic adherence, and angiogenesis are most likely associated with differences in the metastatic behavior of the high and low metastatic OS models.

In this study, we used the pathway-focused GEArray ${ }^{\circledR}$ technique to screen genes related to tumor progression. THBS3, SPARC and SPP1 were identified by CDNA array as genes differentially expressed in osteosarcoma. In addition, expression of selected genes was significantly correlated with clinico-pathological data.

\section{Methods \\ Sample collection}

Seventy-six OS tumor samples were obtained at the Instituto de Oncologia Pediátrica, Grupo de Apoio ao Adolescente e à Criança com Câncer/Universidade Federal de São Paulo (IOP/GRAACC/UNIFESP, São Paulo, SP, Brazil), with informed patient consent and approval of the institutional research ethics board (0261/03). Tissue sections were stained and subjected to standard histopathological evaluation to determine tumor content, as well as the proportion of necrosis and the pathological grade. Tumor specimens were stored at $-80^{\circ} \mathrm{C}$ until a tumor-rich tissue had been selected for RNA extraction, according to the histological assessment by the pathologist. Clinical data for each case was obtained from the medical records.

\section{Diagnostic staging and treatment}

All patients younger than 25 years of age with high-grade OS of the extremities (metastatic and non-metastatic) were prospectively enrolled onto the Brazilian Osteosarcoma Treatment Group study IV [3]. In study IV, patients received carboplatin $\left(500 \mathrm{mg} / \mathrm{m}^{2}\right.$ intravenous infusion on day 1 of weeks $0,3,6,17$, and 26) and cisplatin (100 mg/ $\mathrm{m}^{2}$ intravenous infusion on day 1 of weeks $0,3,6,11$, and 20). Doxorubicin was administered either at a dose of 30 $\mathrm{mg} / \mathrm{m}^{2}$ in short-term intravenous infusion on days 1 and 2 of weeks $0,3,6,14,17$, and 23 in the initial phase of the study or at a dose of $35 \mathrm{mg} / \mathrm{m}^{2}$, following the same schedule administered in a previous group with dexrazoxane. Intravenous infusion infusions of ifosfamide at $3 \mathrm{~g} / \mathrm{m}^{2}$ and mesna, as described [3] were added on days 1, 2, and 3 and on weeks 11, 14, 20, and 26, respectively. The orthopedics team in collaboration with the pediatric oncology team determined the appropriate surgical procedure for each patient. Non-conventional endoprosthesis, resection of expendable bones, plaques, and bone graft fixation (autograft or bone bank) were used. Whenever possible, all pulmonary metastases were surgically removed, after resection of the primary tumor. 


\section{RNA preparation}

Total RNA from OS tumors was isolated using the TRIzol ${ }^{\circledR}$ Reagent (Invitrogen) and re-suspended in sterile DEPC water. The amount of RNA was determined by spectrophotometry and sample integrity was monitored through visualization of ribosomal RNAs (28S and $18 \mathrm{~S}$ ) by electrophoresis.

\section{Gene expression profiling}

Pathway-focused expression profiling was performed using a subset of 15 tumors: 9 samples from patients with metastatic disease at diagnosis ( 3 initial biopsy specimens, 3 primary bone tumor resection specimens, and 3 biopsies of metastasis detected at diagnosis); and 6 samples from patients classed as having non-metastatic disease at diagnosis (3 initial biopsy specimens and 3 primary bone tumor resection specimens). For each group, a pool of an equal amount of RNA from 3 tumor samples from each phase of disease was used. In addition, a pool of RNA derived from osteoblastic cellular preparations from two bone resections unrelated to a pathological condition served as a tissue-specific expression control.

GEArray $^{\circledR} \mathrm{Q}$ Series pathway arrays containing 112 sites each ( 3 blanks, 3 negative reference spots, 10 endogenous genes, and 96 pathway-specific human genes) were obtained from SuperArray Bioscience Corporation (Frederick, USA). The GEArray ${ }^{\circledR} \mathrm{Q}$ Series Human Tumor Metastasis Gene Array, Chemokines and Receptors Gene Array and Angiogenesis Gene Array were designed to assess the different expression levels of 96 genes that either interact with or are controlled by each specific biological pathway. Protocol and data analysis of arrays were performed according to the manufacturer's instructions and the gene list and array position for expression profiling are available at Superarray Bioscience Corporation website [14].

Biotin-labeled cDNA were generated with total RNA $(1 \mu \mathrm{g})$ from corresponding samples using GEArray ${ }^{\circledR}$ Ampolabelling LPR Kit (SuperArray Bioscience Corporation ${ }^{\circledR}$ ). The cDNA probes were then denatured, and hybridized in GEAhyb solution to nylon membranes spotted with genespecific fragments. Hybridization was performed overnight at $60^{\circ} \mathrm{C}$ with continuous agitation. Membranes were washed twice in $2 \times \mathrm{SSC} / 1 \% \mathrm{SDS}$ for 15 minutes each, followed by another wash in $0.1 \times$ SSC/0.5\%SDS for 15 minutes. Hybridized probes were visualized with the CPD-Star Chemiluminescent Detection Kit (SuperArray Bioscience Corporation $^{\circledR}$ ).

Array images were recorded using Kodak X-OMAT LS film (Amersham Biosciences, Piscataway, NJ, USA) and SprintScan 35 Plus (Polaroid Canada Inc., Mississauga, ON, Canada). Images were converted into grayscale and 16-bit tiff format, and the numerical data representing the expression levels of each gene on the arrays were quantified using the GEArray ${ }^{\circledR}$ Expression Analysis Suite (SuperArray Bioscience Corporation ${ }^{\circledR}$ ). Raw data were intranormalized with the mean signal intensity of the ACTB gene after subtracting the mean intensities of the negative control spots (pUC18 plasmid DNA and blank spots. Inter-normalization was performed with control normal bone signal intensities.

The change in the level of a given gene transcript from one membrane/experiment was estimated by comparing the signal intensities of paired specimens, such as: (1) biopsy sample from patients with metastasis at diagnosis versus normal bone; (2) primary tumor resection sample from patients with metastasis at diagnosis versus normal bone; (3) metastatic sample from patient with metastasis at diagnosis versus normal bone; (4) biopsy sample from patients with non metastasis at diagnosis versus normal bone; (5) primary tumor resection sample from patients with non metastasis at diagnosis versus normal bone. The differentially expressed genes were determined based on two criteria: gene performance outline filtering was applied to exclude the lower intensity or absent values, and only genes with fold changes larger than -2 and +2 were considered for increased/decreased expression.

The expression datasets presented in this publication have been deposited in NCBIs Gene Expression Omnibus [15] and are accessible through GEO Series accession number GSE5045.

\section{Quantitative real-time PCR}

From 43 different patients, 20 biopsies, 22 primary tumors, and 19 metastases specimens were included for real-time PCR analysis. Due to low quantity of RNA, the relative quantification of THBS3 was performed on 52 samples derived from 40 patients, SPARC was performed on 55 samples derived from 43 patients, and SPP1 was performed on 53 samples derived from 41 patients.

Total RNA was reverse-transcribed using the Gene Amp ${ }^{\circledR}$ Gold RNA PCR Core Kit (Applied Biosystem ${ }^{\circledR}$ ) according to the manufacturer's instructions. The RT ${ }^{2}$ PCR Primer Sets (SuperArray Bioscience Corporation ${ }^{\circledR}$ ) for human THBS3,SPARC, SPP1 (target genes) and $\beta$-actin (ACTB endogenous gene) were used. Real-time PCR amplification and data analysis were performed using the ABI Prism 7900 and 7700 HT Sequence Detector System (Applied Biosystems $^{\circledast}$ ). Each sample was mixed with $24 \mu \mathrm{l}$ of master mix $\left(\mathrm{SYBR}^{\circledR}\right.$ Green PCR Master Mix - Applied Biosystems $^{\circledast}$ ). The PCR conditions were 2 minutes at $50^{\circ} \mathrm{C}, 10$ minutes at $95^{\circ} \mathrm{C}$, followed by 40 cycles of 15 seconds at $95^{\circ} \mathrm{C}$ and 1 minute at $60^{\circ} \mathrm{C}$. Experiments were performed in triplicate, for both the target and the endogenous genes. A no-template control was included in each 
amplification reaction. The PCR efficiencies of the four genes were comparable ( $\geq 95 \%)$.

\section{Real-time PCR data analysis}

To determine the relative quantification of gene expression, the comparative $\mathrm{Ct}$ (cycle threshold) method was used [16]. Briefly, this method uses arithmetic formulas to determine relative quantification. To normalize the varying cDNA quantities, an endogenous control gene ( $\beta$ actin - ACTB) was run concurrently with the target gene. For each sample, the $\mathrm{Ct}$ was determined for both the target gene and the endogenous gene (median of the 3 reactions). The $\triangle \mathrm{Ct}$ was determined by subtracting the ACTB $\mathrm{Ct}$ from the specific target gene Ct. Identical calculations were made for a known positive control reference sample (QPCR Human Reference Total RNA, Stratagene, La Jolla, $\mathrm{CA}, \mathrm{USA}$ ). The $\Delta \mathrm{Ct}$ of the control reference was then subtracted from the $\Delta \mathrm{Ct}$ of the target gene, yielding the $\Delta \Delta \mathrm{Ct}$, and the relative quantitative value was expressed as $2^{-\Delta \Delta \mathrm{Ct}}$.

\section{Statistical analysis}

Data analysis was performed using Minitab Statistical Software (14.0). Clinical variables correlated with gene expression were: age at diagnosis, gender, histological OS subtype, site of the primary disease, metastatic status at diagnosis, response to chemotherapy, and type of samples (initial biopsy, primary bone tumor resection and metastasis sample present at diagnosis). Overall survival was defined as the time from diagnosis until the date of either the last follow-up or death. The duration of event-free survival was defined as the time from diagnosis until the date of relapse or death. If these patients had metastatic disease at diagnosis, the event was considered as time 0 . For the relapse free survival analysis, the duration was defined as the time from diagnosis until the occurrence of metastasis or local relapse.
All samples from each biopsy, primary tumor resection, and at metastasis were evaluated using gene expression profile findings, and these variables were correlated with survival. Overall survival, event-free survival and relapsefree survival curves were generated by applying the Kaplan-Meier method, and were then compared by the logrank test. Continuous data were evaluated and compared using ANOVA, Mann-Whitney or Mood's Median test. Categorical data were studied using Chi-square or Fisher exact tests. Statistical significance was taken as $\mathrm{p}<0.05$.

\section{Results}

A summary of the clinico-pathological parameters for each case is detailed in Table 1 . There was no significant difference in relative expression levels of THBS3, SPARC and SPP1 when the initial biopsy specimens, the primary bone tumor resection specimens, and the biopsies of metastasis were compared. Therefore we examined differential levels of gene expression of all three genes in primary tumor RNA (from both biopsy specimens and bone tumor resections) to assess their utility as biomarkers of prognosis. Thus in these analyses expression levels in primary tumor RNA were used as predictors of overall survival, event-free survival and relapse-free survival.

\section{Pathway-focused GEarray ${ }^{\circledR}$ analysis}

Samples from biopsy, primary tumor resection and metastatic site (metastatic group only) from the metastatic and non-metastatic groups were each processed for gene expression analysis using the GEArray ${ }^{\circledR} \mathrm{Q}$ Series Human Tumor Metastasis Gene Array, Chemokines and Receptors Gene Array, and Angiogenesis Gene Array. Thirty-two genes from the angiogenesis membrane, 51 from the tumor metastasis membrane and 25 genes from the chemokine membrane were identified as differentially expressed. The values of the selected THBS3, SPARC, and SPP1 genes are presented in Table 2. Correlation coeffi-

Table I: Clinico-pathological description of osteosarcoma patients.

\begin{tabular}{|c|c|c|c|}
\hline Parameter & Number of patients & Parameter & Number of patients \\
\hline Age at diagnosis (years) & & Huvos grade & \\
\hline $0-10$ & 6 & $|-| \mid$ & 27 \\
\hline $11-20$ & 33 & III-IV & 7 \\
\hline$\geq 21$ & 4 & Not informative & 9 \\
\hline Gender & & Metastasis at $\mathrm{d}$ & \\
\hline Male & 25 & Yes & 17 \\
\hline Female & 18 & No & 26 \\
\hline Histological subtype & & Site of primary & \\
\hline Osteoblastic & 23 & Femur & 20 \\
\hline Chondroblastic & 7 & Tibia & 15 \\
\hline Telangiectatic & 4 & Fibula & 2 \\
\hline Giant cells & I & Humerus & 4 \\
\hline Other & 6 & Iliac bone & 1 \\
\hline Not informative & 2 & Other & 1 \\
\hline
\end{tabular}


Table 2: Pathway-focused GEArrays ${ }^{\circledR}$ : Comparison of three of the up-regulated genes in osteosarcoma samples categorized as metastatic at diagnosis and non-metastatic at diagnosis

\begin{tabular}{lccccc}
\hline Gene symbol & \multicolumn{3}{c}{ Metastatic at diagnosis } & \multicolumn{2}{c}{ Non-metastatic at diagnosis } \\
\cline { 2 - 6 } & B/C & S/C & M/C & B/C & S/C \\
\hline THBS3 & 23.8 & 53.15 & 7.1 & $\mathrm{AE}$ & $\mathrm{AE}$ \\
SPARC & 13.4 & 18.6 & 15.3 & 6.8 & 5.0 \\
SPPI & 7.2 & 3.7 & 9.11 & 4.3 & 5.3 \\
\hline
\end{tabular}

B, sample from biopsy, $\mathbf{S}$, sample from primary tumor resection, $\mathbf{M}$, sample from metastatic site, $\mathbf{C}$, normal bone control, AE, absence of expression. The values are expressed as linear ratios against normal bone controls.

cients did not detect any relationship between the relative expression levels of these genes considered at any time point or in combination $\left(-0.11<\right.$ Adjusted $\left.\mathrm{R}^{2}<0.14\right)$.

\section{THBS3 mRNA expression in osteosarcoma patients}

To confirm THBS3 over-expression, we performed quantitative real-time PCR on 52 samples from 40 patients. Of the 52 tumors analyzed, 30 (58\%) showed high expression of THBS3 and 22 samples (42\%) showed low expression of THBS3. A comparison of the THBS3 expression levels in biopsy versus primary tumor resection or metastatic samples showed significant differences $(\mathrm{p}=0.0001$, $\mathrm{p}=0.0001$, respectively). However, this correlation was not significant in primary tumor resection samples versus metastases $(\mathrm{p}=0.72)$ (Figure $1 \mathrm{~A})$. In addition, different levels of THBS3 expression were observed when biopsy and surgical samples from the same patients were compared $(\mathrm{n}=7)(\mathrm{p}=0.031)$.

A trend for higher expression was observed in samples from patients with metastatic disease at diagnosis $(\mathrm{p}=$ 0.058). However, there was no significant correlation with other clinical parameters, such as age at diagnosis, gender, Huvos grade, site of primary tumor, histological type and presence of metastasis at diagnosis. Patients with OS and high levels of expression of THBS3 in biopsy samples stratified using the $75^{\text {th }}$ percentile as cutoff value $(\geq 1.0)$, showed worse overall survival $(p=0.03)$, event-free survival $(\mathrm{p}=0.02)$ and relapse free survival at diagnosis $(\mathrm{p}=$ 0.003 ) (Figure 2A). Patients containing high levels of THBS3 expression in surgical specimens stratified using the $50^{\text {th }}$ percentile as cutoff value $(\geq 0$, over-expression versus down-expression), showed worse relapse free survival $(\mathrm{p}=0.05)$ (Figure 2A).

\section{SPARC mRNA expression in osteosarcoma patients}

To confirm SPARC over-expression, we performed quantitative real-time PCR on 55 samples from 43 patients. High expression of the SPARC gene was found in 51 of 55 tumor samples (96.3\%). SPARC over-expression did not correlate with the different periods of disease (biopsy, surgery and metastasis) (Figure $1 \mathrm{~B}$ ), presence of metastasis at diagnosis, and the clinico-pathological parameters, such as Huvos grade, age, gender, histological OS subtype, site of primary disease, as well as, the overall survival ( $\mathrm{p}=$ 0.81 ) (Figure 2B). Patients with high levels of SPARC gene expression stratified using the $75^{\text {th }}$ percentile as cutoff value $(\geq 1.5)$, revealed worse event-free survival $(p=0.03)$ and relapse free survival $(\mathrm{p}=0.07)$ (Figure $2 \mathrm{~B}$ ).

\section{SPPI mRNA expression in osteosarcoma patients}

To confirm SPP1 over-expression, we performed quantitative real-time PCR on 53 samples from 41 patients. The SPP1 gene was over-expressed in 47 of $53(89 \%)$ and under-expressed in $6 / 53(11 \%)$ of OS samples. In addition, there was a significantly greater level of SPP1 in biopsy samples than in both primary tumor resections and metastatic samples $(\mathrm{p}=0.002, \mathrm{p}=0.0002$, respectively). However, SPP1 expression levels did not reach significance when primary tumor resection samples were compared to metastases $(\mathrm{p}=0.11$ ) (Figure $1 \mathrm{C})$. A recurrent differential level of THBS3 expression was also observed when comparing biopsy and primary tumor resection samples from the same patients $(\mathrm{n}=7)(\mathrm{p}=$ 0.031). SPP1 over-expression did not correlate with the presence of metastasis at diagnosis and the clinico-pathological parameters, such as Huvos grade, age, gender, histological OS subtype and site of primary disease. Patients with OS showing high levels of expression of SPP1 in biopsy samples, stratified using the $25^{\text {th }}$ percentile as cutoff value $(\geq 1.1)$, revealed better overall survival ( $\mathrm{p}=$ $0.001)$, event-free survival $(\mathrm{p}=0.02)$ and relapse free survival $(\mathrm{p}=0.005)$ (Figure $2 \mathrm{C})$.

\section{Discussion}

In this study, THBS3, SPARC and SPP1 were identified by pathway-focused GEArray $^{\circledR}$ as genes differentially expressed in OS.

The gene for human thrombospondin 3 (THBS3) is a member of a family that encodes an extracellular matrix glycoprotein mediating interactions between cells and the extracellular matrix $[17,18]$. The thrombospondin family of proteins has been implicated in a number of fundamental biological processes: blood coagulation, embryonic development, tissue differentiation, tumor growth 


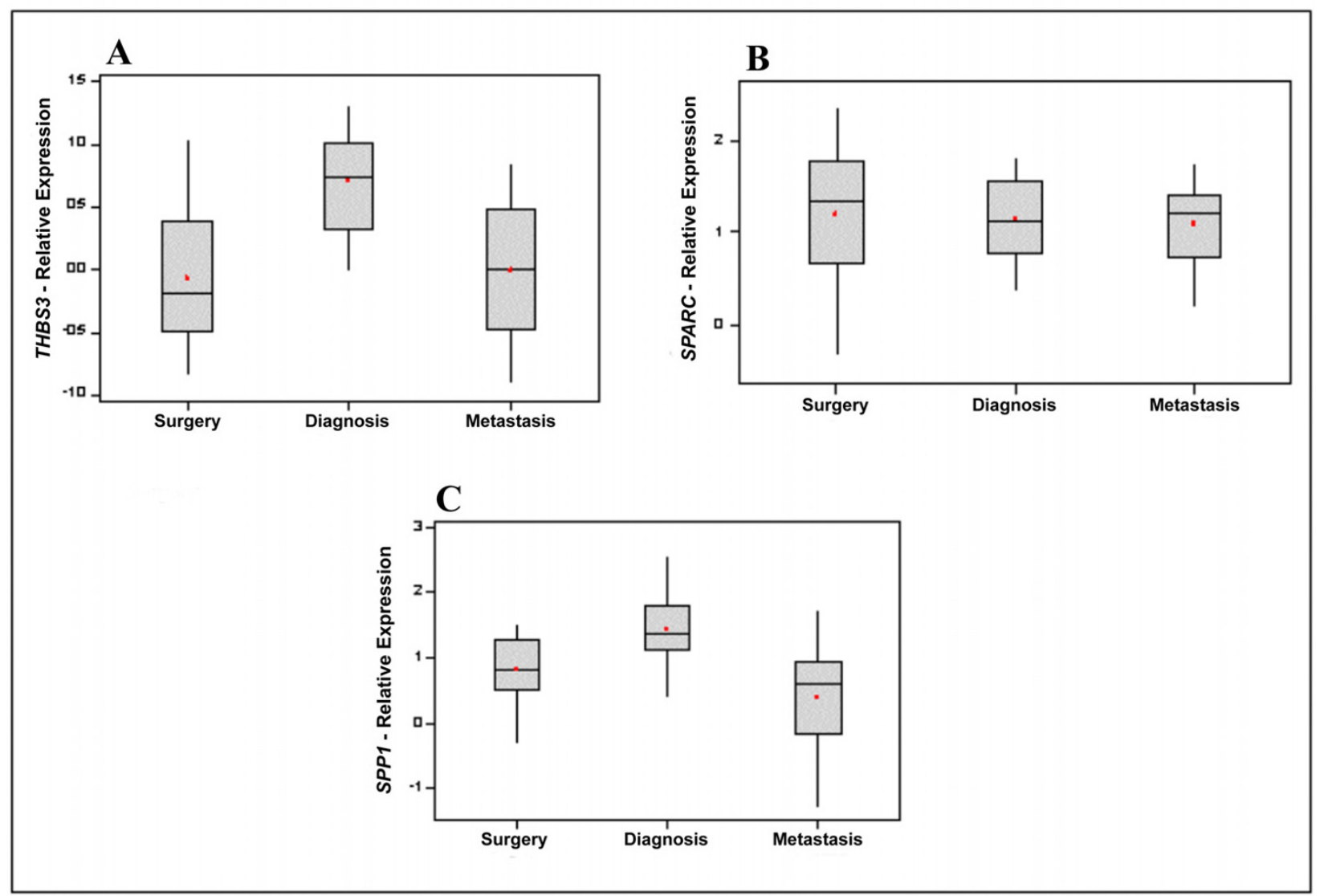

\section{Figure I}

Relationship between gene expression and clinical evolution of disease. The box plot shows the median, upper and lower quartiles and minimum and maximum values for related gene expression. A- Relative expression of THBS3 in groups of OS patients represented by samples obtained from the biopsy diagnosis $(n=16)$, primary tumor surgery $(n=19)$ and metastases $(n=$ 17 ) ; B- Relative expression of SPARC in groups of OS patients represented by samples obtained from the biopsy diagnosis ( $\mathrm{n}$ $=26)$, primary tumor surgery $(n=16)$ and metastases $(n=13)$; C- Relative expression of SPPI in groups of OS patients represented by samples obtained from the biopsy diagnosis $(n=16)$, primary tumor surgery $(n=20)$ and metastases $(n=17)$.

and metastases, angiogenesis, nerve development, wound healing, and inflammation [17-19].

Osteonectin (SPARC) is a $32 \mathrm{kDa}$ protein important for bone calcification [20]; it is a multifunctional glycoprotein that belongs to the matricellular proteins, defined as a group of extracellular regulatory macromolecules relevant to the extracellular matrix structure [21]. It is involved in a variety of biological processes including tissue remodeling, cell adhesion, proliferation, differentiation, matrix synthesis, angiogenesis, tumor cell migration and invasion $[22,23]$.

The SPP1 gene (osteopontin) is a non-collagenous bone matrix protein with several functions, such as bone remodeling, angiogenesis, cell adhesion, tumor migration and invasion [24-26]. The functional diversity of osteopontin in bone has many features in common with the repair processes involved in inflammatory responses [27]. It is produced by numerous cell types, osteoblasts, osteoclasts, T lymphocytes, NK cells and epithelial cells from breast, kidney, skin, nerve cells and endothelial cells [2426].

Invasion and metastases are inherent features of malignant diseases and involve both intercellular and cellmatrix interaction. The molecular mechanisms include transcriptional modulation of adhesive and anti adhesive molecules, proteases and angiogenic factors [28].

As a primary tumor grows, it needs to develop a blood supply that can support its metabolic needs - angiogen- 

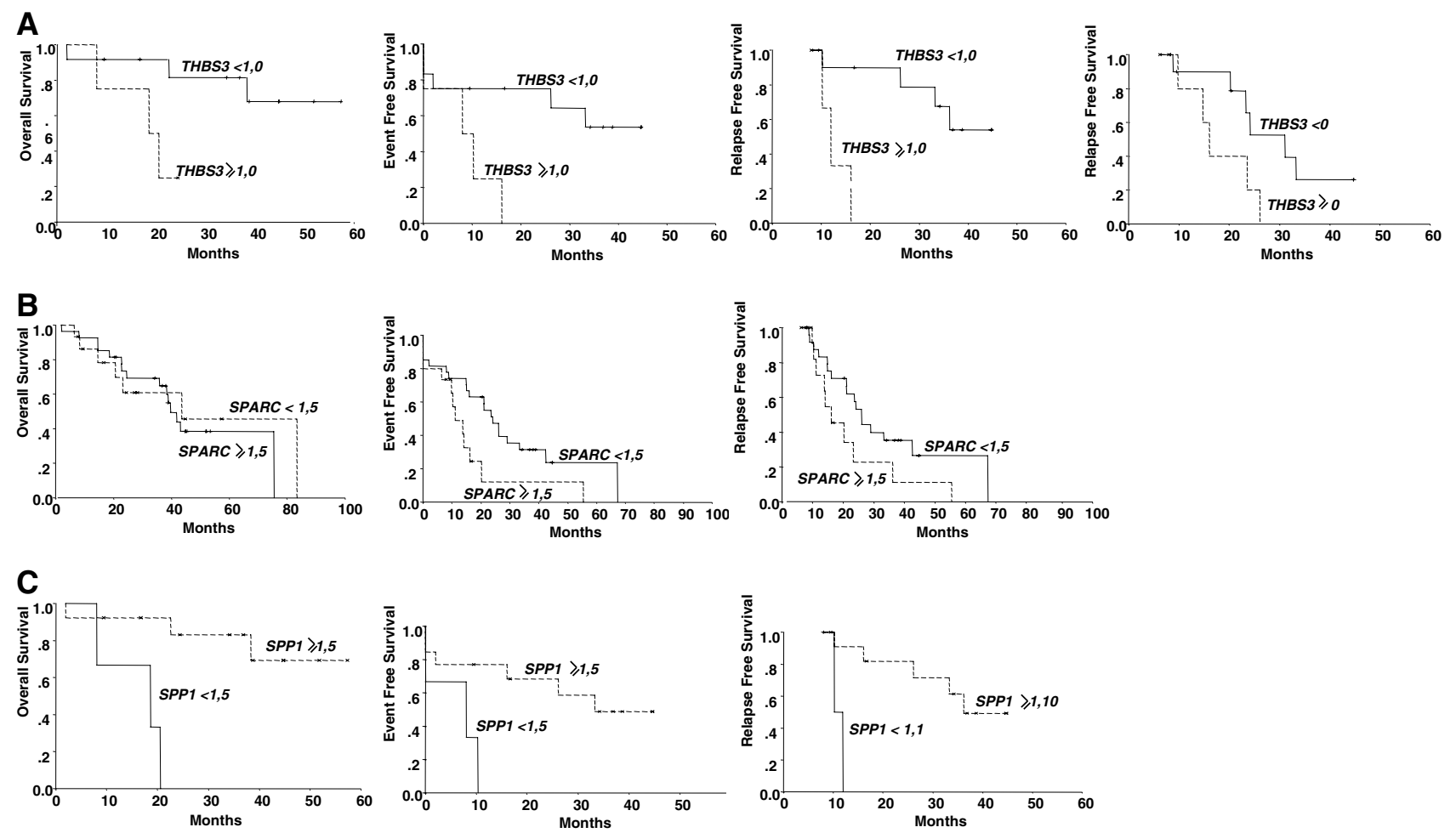

\section{Figure 2}

Overall, event-free survival and relapse-free survival analyses of OS patients correlated with gene expression profiling of either biopsy or primary tumor resection onset groups. A- Overall, event-free survival and relapse-free survival of biopsy onset group with over-expression of THBS3, and relapse-free survival of primary tumor resection onset group with over-expression of THBS3. B- Overall, event-free survival and relapse-free survival of biopsy onset group with over-expression of SPARC.COverall, event-free survival and relapse-free survival of biopsy onset group with over-expression of the SPPI gene.

esis. These new blood vessels may also provide an escape route by which cells can leave the tumor and enter into the body's circulatory blood system, a process known as "intravasation". The cells need to survive in the circulation until they are arrested in a new organ; where they may extravasate from the circulation into the surrounding tissue. Once in the new site, cells must initiate and maintain growth to form pre-angiogenic micrometastases; this growth must be sustained by the development of new blood vessels in order to form a macroscopic tumor [6].

Thrombospondin 3 is structurally similar to cartilage oligomeric matrix protein (COMP/THBS5), but its function is unknown. A study in THBS3-null mice provided evidence for the role of THBS3 in the regulation of skeletal maturation in mice [29]. The role of THBS1, the most widely studied gene in this family, in angiogenesis and tumor progression remains controversial. THBS1 has been considered an inhibitor of angiogenesis and tumor progression in bladder and lung cancer [30,31]. In contrast, it has also been considered a stimulator of both processes in pancreatic carcinoma, melanoma and hepa- tocellular carcinoma [32-34]. One study found high THBS1 levels in hepatocellular carcinoma and venous invasion in tumors with low levels of vascular endothelial growth factor (VEGF) protein expression [34].

The group with metastasis at diagnosis showed high levels of THBS3 expression in biopsy samples, demonstrating the importance of this gene in tumor growth and progression. These data strongly suggest that high THBS3 expression can predict worse overall survival, event-free survival and relapse free survival at diagnosis. After chemotherapy, levels of THBS3 declined in some tumors. The groups of patients who maintain over expression have worse relapse free survival, suggesting that keeping THBS3 at high levels maintains the capacity of angiogenesis activated by THBS3. This is part of the process of tumor progression and perhaps may be used as a prognostic factor and therapeutic target in OS.

To the best of our knowledge, this is the first report about the THBS3 gene function as a stimulator of tumor progression in osteosarcoma. Its effects, like those of THBS1, may 
also depend on concentration, type of domain activated or available, and type of receptors present on endothelial cells $[33,35,36]$. The study of these parameters together with the expression levels of THBS3 in OS should be considered, given one's interest in anti-angiogenic agents in the OS treatment protocol.

Osteonectin is produced by osteoblasts and young osteocytes [37]. SPARC is expressed at high levels in bone tissue [38].

In this study no differences were observed between the levels of expression in biopsy, primary tumor resection and metastatic site samples, showing that high levels of $S P A R C$ are not required for tumor progression. However, higher SPARC expression $(\geq 1.5)$ has worse event-free survival and shows a tendency to early relapse free survival. This strongly suggests that SPARC expression is necessary for tumor growth and maintenance, and may be used as a promising prognostic marker in OS.

Over-expression of SPARC promotes tumor growth and was reported in a variety of human malignancies, including melanoma, breast cancer, esophageal cancer and gastric carcinoma [28,39-41], but other reports suggest that decreased SPARC expression is associated with increased tumorigenesis and metastases in human ovarian carcinoma and neuroblastoma $[42,43]$. The promoting or inhibiting effects of osteonectin in different cancers seem dependent upon the cell type, the concentration, and the presence of full-length or proteolytic fragments of osteonectin [44].

Osteopontin (SPP1) is a major protein of the extracellular bone matrix, and gene expression is up regulated in specific phases of osteoblastic lineage differentiation [45-47]. SPP1 has become of interest in tumorigenesis, and expression of the protein has been observed in human cancer [48].

In this study, we observed that biopsy samples had higher expression of SPP1 than samples from primary tumor resection and metastasis, showing that high levels of SPP1 are not necessary for tumor progression in OS. At the same time, we noticed that the level of expression is an independent variable from the presence of metastatic disease at diagnosis; these two characteristics indicate that high expression of SPP1 is not necessary for tumor progression or metastatic disease in OS. In contrast, high expression of SPP1 in other tumors, such as breast cancer, lung cancer, prostate cancer, hepatocellular carcinoma, colon cancer has been associated with tumor progression and metastases [49-52]. Another contrast is that we observed over expression of SPP1 correlates with better overall survival, event-free survival and relapse free survival. A study of 57 samples from OS patients by immunohistochemistry reported over expression of SPP1 and VEGF. However, SPP1 levels showed no correlation with overall survival and event-free survival. SPP1 is normally expressed in normal bone and, as part of the inflammatory response, participates in the remodeling process of the bone [53]. The functional diversity of SPP1 in bone formation and remodeling appears to be related to the fundamental roles of this protein in host defense and tissue repair; in fact, the bone remodeling process has many features in common with the repair processes involved in inflammatory responses [27].

Identification of the molecular determinants of invasion and metastatic pathways will guide the development of a rational strategy for devising specific therapies that target the pathways leading to OS.

\section{Conclusion}

In conclusion, through the screening of arrays we identified genes related to tumorigenesis. Three genes were validated with real-time RT-PCR and correlated with clinicopathological parameters; whereby the clinical significance of over expression of THBS3 for tumor growth and progression, the necessity of SPARC for tumor growth and maintenance, and the potential for SPP1 as a biological marker of OS were demonstrated.

\section{Abbreviations}

IOP - Instituto de Oncologia Pediátrica

GRAACC - Grupo de Apoio ao Adolescente e à Criança com Câncer

UNIFESP - Universidade Federal de São Paulo

cDNA - complementary deoxyribonucleic acid

PCR - polymerase chain reaction

THBS3 - thrombospondin 3

SPARC - osteonectin, secreted protein acidic and rich in cysteine

SPP1 - osteopontin, secreted phosphoprotein 1

OS - osteosarcoma

ITGB4 - integrin beta-4

CTGF - connective tissue growth factor

ITGA5 - integrin alpha-5 
VIL2 - villin 2, ezrin, cytovillin

ITGB2 - integrin beta-2

LGALS3 - galectin-3

ADAM 8 - a disintegrin and metalloprotease domain 8

CLU - clusterin

FARP1 - pleckstrin domain-containing protein 1

$C P$ - ceruloplasmin

RNA - ribonucleic acid

DEPC water - diethylpyrocarbonate water

ACTB - beta-actin

DNA- deoxyribonucleic acid

pUC18 - hypothetical protein PC405478.00.0 [Plasmodium chabaudi chabaudi]

RT-PCR - reverse transcriptase-polymerase chain reaction

Ct - cycle threshold

mRNA - messenger ribonucleic acid

GEO - Gene Expression Omnibus

NK cells - natural killer cells

COMP/THBS5 - cartilage oligomeric matrix protein

THBS1 - thrombospondin 1

VEGF - vascular endothelial growth factor

\section{Competing interests}

The author(s) declare that they have no competing interests.

\section{Authors' contributions}

CADT: designed and performed experiments, analyzed data, and wrote manuscript

MY, SCM and CHL: analyzed data and wrote the final manuscript

AMJ: performed statistical analysis as required for the revised manuscript
ASP: selected the cases and worked closely with SRCT

SRCT, JADA, MZ and JAS: designed experiments, analyzed data, and wrote manuscript

JAS: project leader, analyzed data, and wrote manuscript

All authors read and approved the final manuscript.

\section{Acknowledgements}

This work was supported by awards from the Coordenação de Aperfeiçoamento de Pessoal de Nível Superior (CAPES) and Grupo de Apoio ao Adolescente e a Criança com Câncer (GRAACC) to C.A.D-T., Fundação de Amparo e Pesquisa de São Paulo (FAPESP) and National Cancer Institute of Canada (NCIC) with funds from the Canadian Cancer Society.

\section{References}

I. Meyers PA, Gorlick R: Osteosarcoma. Pediatr Clin North Am 1997, 44(4):973-989.

2. Instituto Brasileiro de Geografia e Estatística: Censo Demográfico. http://wwwibgegovbr 2000.

3. Petrilli AS, de Camargo B, Filho VO, Bruniera P, Brunetto AL, JesusGarcia R, Camargo OP, Pena W, Pericles P, Davi A, Prospero JD, Alves MT, Oliveira CR, Macedo CR, Mendes WL, Almeida MT, Borsato ML, dos Santos TM, Ortega J, Consentino E: Results of the Brazilian Osteosarcoma Treatment Group Studies III and IV: prognostic factors and impact on survival. J Clin Oncol 2006, 24(7): I| $161-1 \mid 68$

4. Wada T, Isu K, Takeda N, Usui M, Ishii S, Yamawaki S: A preliminary report of neoadjuvant chemotherapy NSH-7 study in osteosarcoma: preoperative salvage chemotherapy based on clinical tumor response and the use of granulocyte colony-stimulating factor. Oncology 1996, 53(3):221-227.

5. Gorlick R, Meyers PA: Osteosarcoma necrosis following chemotherapy: innate biology versus treatment-specific. J Pediatr Hematol Oncol 2003, 25(I I):840-84I.

6. Chambers AF, Groom AC, MacDonald IC: Dissemination and growth of cancer cells in metastatic sites. Nat Rev Cancer 2002, 2(8):563-572.

7. Cai Z, Chiu JF, He QY: Application of proteomics in the study of tumor metastasis. Genomics Proteomics Bioinformatics 2004 2(3): $152-166$

8. Schena M, Shalon D, Davis RW, Brown PO: Quantitative monitoring of gene expression patterns with a complementary DNA microarray. Science 1995, 270(5235):467-470.

9. Tillmar L, Welsh N: In vitro cultured rat islets express genes that both prevent and promote angiogenesis. Jop 2004, 5(2):8I-9I.

10. Vacca A, Ria R, Semeraro F, Merchionne F, Coluccia M, Boccarelli A Scavelli C, Nico B, Gernone A, Battelli F, Tabilio A, Guidolin D, Petrucci MT, Ribatti D, Dammacco F: Endothelial cells in the bone marrow of patients with multiple myeloma. Blood 2003, 102(9):3340-3348.

II. Blazquez C, Gonzalez-Feria L, Alvarez L, Haro A, Casanova ML, Guzman M: Cannabinoids inhibit the vascular endothelial growth factor pathway in gliomas. Cancer Res 2004, 64(16):5617-5623.

12. Maxion HK, Kelly KA: Chemokine expression patterns differ within anatomically distinct regions of the genital tract during Chlamydia trachomatis infection. Infect Immun 2002, 70(3): I538-1546.

13. Khanna C, Khan J, Nguyen P, Prehn J, Caylor J, Yeung C, Trepel J, Meltzer P, Helman L: Metastasis-associated differences in gene expression in a murine model of osteosarcoma. Cancer Res 200I, 6 I (9):3750-3759.

14. Superarray: Superarray Bioscience Corporation: [http:// www.superarray.com].

15. Omnibus NCBIGE: NCBIs Gene Expression Omnibus [http:// www.ncbi.nlm.nih.gov/geo/].

16. Livak KJ, Schmittgen TD: Analysis of relative gene expression data using real-time quantitative PCR and the 2(-Delta Delta C(T)) Method. Methods 200I, 25(4):402-408. 
17. Adams J, Lawler J: Extracellular matrix: the thrombospondin family. Curr Biol 1993, 3(3): 188-190.

18. Bornstein P, Sage EH: Thrombospondins. Methods Enzymol 1994, 245:62-85

19. Frazier WA: Thrombospondins. Curr Opin Cell Biol 1991, 3(5):792-799.

20. Termine JD, Kleinman HK, Whitson SW, Conn KM, McGarvey ML, Martin GR: Osteonectin, a bone-specific protein linking mineral to collagen. Cell I98I, 26(I Pt I):99-105.

21. Bornstein P, Sage EH: Matricellular proteins: extracellular modulators of cell function. Curr Opin Cell Biol 2002, I4(5):608-616.

22. Yan $\mathrm{Q}$, Sage EH: SPARC, a matricellular glycoprotein with important biological functions. J Histochem Cytochem 1999, 47(12): I 495-1506.

23. Bradshaw $A D$, Sage EH: SPARC, a matricellular protein that functions in cellular differentiation and tissue response to injury. J Clin Invest 200I, 107(9): 1049-1054.

24. Denhardt DT, Noda M: Osteopontin expression and function: role in bone remodeling. J Cell Biochem Suppl 1998, 30-31:92-102.

25. O'Regan A, Berman JS: Osteopontin: a key cytokine in cellmediated and granulomatous inflammation. Int J Exp Pathol 2000, 81 (6):373-390.

26. Weber GF: The metastasis gene osteopontin: a candidate target for cancer therapy. Biochim Biophys Acta 200I, I552(2):6I-85.

27. Sodek J, Ganss B, McKee MD: Osteopontin. Crit Rev Oral Biol Med 2000, II(3):279-303.

28. Wang CS, Lin KH, Chen SL, Chan YF, Hsueh S: Overexpression of SPARC gene in human gastric carcinoma and its clinic-pathologic significance. Br J Cancer 2004, 9 I (I I): I924- 930.

29. Hankenson KD, Hormuzdi SG, Meganck JA, Bornstein P: Mice with a disruption of the thrombospondin 3 gene differ in geometric and biomechanical properties of bone and have accelerated development of the femoral head. Mol Cell Biol 2005, 25(13):5599-5606.

30. Grossfeld GD, Ginsberg DA, Stein JP, Bochner BH, Esrig D, Groshen S, Dunn M, Nichols PW, Taylor CR, Skinner DG, Cote RJ: Thrombospondin-I expression in bladder cancer: association with p53 alterations, tumor angiogenesis, and tumor progression. J Natl Cancer Inst 1997, 89(3):219-227.

3I. Fontanini G, Boldrini L, Calcinai A, Chine S, Lucchi M, Mussi A, Angeletti CA, Basolo F, Bevilacqua G: Thrombospondins I and II messenger RNA expression in lung carcinoma: relationship with p53 alterations, angiogenic growth factors, and vascular density. Clin Cancer Res 1999, 5(I):155-161.

32. Kasper HU, Ebert M, Malfertheiner $P$, Roessner A, Kirkpatrick $C J$ Wolf HK: Expression of thrombospondin-I in pancreatic carcinoma: correlation with microvessel density. Virchows Arch 200I, 438(2): II6-I20.

33. Straume O, Akslen LA: Expresson of vascular endothelial growth factor, its receptors (FLT-I, KDR) and TSP-I related to microvessel density and patient outcome in vertical growth phase melanomas. Am J Pathol 200I, I 59(I):223-235.

34. Poon RT, Chung KK, Cheung ST, Lau CP, Tong SW, Leung KL, Yu WC, Tuszynski GP, Fan ST: Clinical significance of thrombospondin I expression in hepatocellular carcinoma. Clin Cancer Res 2004, I 0(I2 Pt I):4150-4I57.

35. Qian X, Tuszynski GP: Expression of thrombospondin-I in cancer: a role in tumor progression. Proc Soc Exp Biol Med 1996 21 2(3): 199-207.

36. Chandrasekaran L, He CZ, Al-Barazi H, Krutzsch HC, Iruela-Arispe ML, Roberts DD: Cell contact-dependent activation of alpha3beta I integrin modulates endothelial cell responses to thrombospondin-I. Mol Biol Cell 2000, I I (9):2885-2900.

37. Jundt G, Berghauser KH, Termine JD, Schulz A: Osteonectin--a differentiation marker of bone cells. Cell Tissue Res 1987, 248(2):409-4I5.

38. Sodek ], Zhu B, Huynh MH, Brown T], Ringuette M: Novel functions of the matricellular proteins osteopontin and osteonectin/ SPARC. Connect Tissue Res 2002, 43(2-3):308-319.

39. Massi D, Franchi A, Borgognoni L, Reali UM, Santucci M: Osteonectin expression correlates with clinical outcome in thin cutaneous malignant melanomas. Hum Pathol 1999, 30(3):339-344.

40. lacobuzio-Donahue CA, Argani P, Hempen PM, Jones J, Kern SE: The desmoplastic response to infiltrating breast carcinoma: gene expression at the site of primary invasion and implications for comparisons between tumor types. Cancer Res 2002, 62(18):535I-5357.

41. Yamashita K, Upadhay S, Mimori K, Inoue H, Mori M: Clinical significance of secreted protein acidic and rich in cystein in esophageal carcinoma and its relation to carcinoma progression. Cancer 2003, 97( I 0):24I2-24I9.

42. Mok SC, Chan WY, Wong KK, Muto MG, Berkowitz RS: SPARC, an extracellular matrix protein with tumor-suppressing activity in human ovarian epithelial cells. Oncogene 1996, I 2(9): 1895-1901.

43. Chlenski A, Liu S, Crawford SE, Volpert OV, DeVries GH, Evangelista A, Yang Q, Salwen HR, Farrer R, Bray J, Cohn SL: SPARC is a key Schwannian-derived inhibitor controlling neuroblastoma tumor angiogenesis. Cancer Res 2002, 62(24):7357-7363.

44. Bos TJ, Cohn SL, Kleinman HK, Murphy-Ulrich JE, Podhajcer OL, Rempel SA, Rich JN, Rutka JT, Sage EH, Thompson EW: International Hermelin brain tumor symposium on matricellular proteins in normal and cancer cell-matrix interactions. Matrix Biol 2004, 23(1):63-69.

45. Rodan GA, Noda M: Gene expression in osteoblastic cells. Crit Rev Eukaryot Gene Expr 199I, I(2):85-98.

46. Merry K, Dodds R, Littlewood A, Gowen M: Expression of osteopontin mRNA by osteoclasts and osteoblasts in modelling adult human bone. J Cell Sci 1993, 104 ( Pt 4): I013-1020.

47. Dodds RA, Connor JR, James IE, Rykaczewski EL, Appelbaum E, Dul E, Gowen M: Human osteoclasts, not osteoblasts, deposit osteopontin onto resorption surfaces: an in vitro and ex vivo study of remodeling bone. I Bone Miner Res 1995, I0(I I): I666-I680.

48. Brown LF, Papadopoulos-Sergiou A, Berse B, Manseau EJ, Tognazzi K, Perruzzi CA, Dvorak HF, Senger DR: Osteopontin expression and distribution in human carcinomas. Am J Pathol 1994, 145(3):610-623.

49. Arrawal D, Chen T, Irby $R$, Quackenbush J, Chambers AF, Szabo M, Cantor A, Coppola D, Yeatman TJ: Osteopontin identified as lead marker of colon cancer progression, using pooled sample expression profiling. J Nat/ Cancer Inst 2002, 94(7):5|3-52I.

50. Carlinfante G, Vassiliou D, Svensson O, Wendel M, Heinegard D, Andersson G: Differential expression of osteopontin and bone sialoprotein in bone metastasis of breast and prostate carcinoma. Clin Exp Metastasis 2003, 20(5):437-444.

5I. Pan HW, Ou YH, Peng SY, Liu SH, Lai PL, Lee PH, Sheu JC, Chen CL, Hsu HC: Overexpression of osteopontin is associated with intrahepatic metastasis, early recurrence, and poorer prognosis of surgically resected hepatocellular carcinoma. Cancer 2003, 98(I): I19-127.

52. Boldrini L, Donati V, Dell'Omodarme M, Prati MC, Faviana P, Camacci T, Lucchi M, Mussi A, Santoro M, Basolo F, Fontanini G: Prognostic significance of osteopontin expression in early-stage nonsmall-cell lung cancer. Br J Cancer 2005, 93(4):453-457.

53. Sulzbacher I, Birner P, Trieb K, Pichlbauer E, Lang S: The expression of bone morphogenetic proteins in osteosarcoma and its relevance as a prognostic parameter. J Clin Pathol 2002. 55(5):38I-385.

\section{Pre-publication history}

The pre-publication history for this paper can be accessed here:

http://www.biomedcentral.com/1471-2407/6/237/pre pub 